1 Agência Nacional de Vigilância Sanitária (Anvisa) - Brasília (DF), Brasil.

batista.junior@anvisa.gov.br

2 Universidade de Brasília (UnB), Departamento de Saúde Coletiva, Faculdade de Ciências da Saúde Brasília (DF), Brasil.

daphne.rattner@gmail.com

\section{A Vigilância Sanitária no controle de riscos potenciais em serviços de hemoterapia no Brasil}

\author{
Health Surveillance in the control of potential risks in hemotherapy \\ services in Brazil
}

João Batista Silva Júnior' ${ }^{1}$ Daphne Rattner ${ }^{2}$

RESUMO O artigo descreve a situação sanitária dos serviços de hemoterapia avaliados pela Vigilância Sanitária em 2011 e 2012 por meio do Método de Avaliação de Risco Potencial de Serviços de Hemoterapia (MARPSH), classificando-os em cinco categorias: Baixo, MédioBaixo, Médio, Médio-Alto e Alto. Dos 560 avaliados, houve acréscimo de $9 \%$ nos classificados como de baixo risco e queda de $6 \%$ entre os de alto. Os principais problemas foram encontrados na região Norte, em agências transfusionais e serviços públicos. Destacaram-se não conformidades relacionadas à gestão da qualidade, de pessoal e de equipamentos. Apesar das melhorias observadas, notaram-se serviços críticos com comprometimento à segurança e à eficácia dos produtos e serviços.

PALAVRAS-CHAVE Serviço de hemoterapia; Vigilância sanitária; Controle de riscos; Avaliação.

\begin{abstract}
The article describes the risks of hemotherapy services evaluated by the Health Surveillance in 2011 and 2012 through the Valuation Method of Potential Risks in Hemotherapy Services (MARPSH), classifying them into five categories:Low, Medium-Low, Medium, MediumHigh and High. Of the 560 evaluated, there was an increase of $9 \%$ among the classified as low risk and a decrease of $6 \%$ among the high risk. The main problems were found in the Northern Region, in transfusion agencies (Hospital Blood Banks) and public services. Nonconformities were mostly related to quality management, of personnel and of equipment. Despite the observed improvements, there were services with critical aspects related to their commitment to the safety and effectiveness of products and services.
\end{abstract}

KEYWORDS Hemotherapy service; Health surveillance; Risk management; Evaluation. 


\section{Introdução}

Em 2012, o Brasil produziu cerca de 4,2 milhões de hemocomponentes provenientes do sangue de doadores, com aproximadamente 3,5 milhões de procedimentos transfusionais realizados, o que torna esta terapêutica essencial à saúde pública brasileira (ANVISA, 2012). Os serviços de hemoterapia se configuram como sistemas complexos e de alta vigilância devido à natureza dos procedimentos de cuidados a doadores e a pacientes, e das atividades de produção de terapêuticos injetáveis (MURPHY; STANWORTH; YAZER, 2011), com uso de inúmeros insumos, equipamentos e tecnologias diversificadas.

A hemoterapia brasileira, até a década de 1980, era marcada por influências mercantilistas, descaso dos poderes públicos, insuficiência e inoperância técnica, além de arcabouço legal fragilizado. Da mesma forma, a Vigilância Sanitária (Visa) de sangue estava desaparelhada e desorganizada (SANTOS; MORAES; COELHO, 1991). Segundo Santos, Moraes e Coelho (1992), somente após a criação do Programa Nacional de Sangue (Pró-Sangue) e o fortalecimento das fiscalizações em serviços pela Visa, começou-se a avançar na perspectiva de qualidade e segurança transfusional no Brasil. Um dos cenários problemáticos apontados na I Conferência de Vigilância Sanitária, em 2001, foi a falta de controle sanitário efetivo das atividades relacionadas a sangue e a hemoderivados no Brasil (ANVISA, 2001).

Embora as transfusões sanguíneas sejam, atualmente, uma prática clínica segura, riscos fazem parte do ciclo do sangue e um desvio ou falha pode comprometer a saúde de doadores, profissionais envolvidos e pacientes. Alguns exemplos: os pacientes podem receber sangue com agentes infecciosos se os resultados dos testes analíticos na amostra de sangue de um doador infectado por um agente transmissível não forem interpretados corretamente, ou se os materiais, insumos e equipamentos para a realização dos testes forem inadequados; os pacientes podem sofrer de insuficiência renal (ou até mesmo morrer) devido à determinação errônea do grupo sanguíneo, ou podem ter uma infecção bacteriana se o sangue for coletado, processado, armazenado e administrado em ambientes ou com procedimentos que comprometem a esterilidade do produto, entre outros danos (RAMOA; MAIA; LOURENÇO, 2012).

Segundo Zou et al. (2010) e Epstein e Holmberg (2010), a necessidade de constante ação de vigilância torna-se cada vez mais evidente, tanto no sentido de melhorar quanto no de manter os avanços alcançados. As flutuações observadas na qualidade e nos mecanismos de controle dos serviços de hemoterapia chamam a atenção para a necessidade de monitoramento contínuo e de avaliação periódica.

Em 2012, a Medicines and Healthcare Products Regulatory Agency (MHRA) (ENGLAND, 2012), autoridade nacional de vigilância sanitária da Inglaterra, publicou relatório sobre as principais não conformidades observadas desde 2005 neste país, oriundas do Sistema de Hemovigilância e dos relatórios das inspeções sanitárias dos serviços de hemoterapia. Segundo informações do referido documento, cerca de $60 \%$ dos problemas referiam-se a erros humanos por imperícia técnica, falta de atenção, estresse e falta de comunicação entre os profissionais. Analisando os anos de 2010 a 2011, os dados de inspeção apontaram que os maiores problemas foram encontrados na garantia de qualidade, manutenção de equipamentos, validação de processos e documentação (ENGLAND, 2012). A avaliação de erros e eventos adversos, bem como a de falhas nas barreiras de controle, é empregada em muitos métodos de avaliação dos riscos em sistemas produtivos (OBSY ET AL., 2007).

A avaliação ou o julgamento normativo, a partir de critérios e normas, deve utilizar dispositivos capazes de fornecer informações cientificamente válidas e socialmente 
legítimas, inserindo a avaliação em um sistema social organizado para apoio à decisão (CONTANDRIOPOULOS ET AL., 1997).

Os instrumentos de Visa, necessariamente, estão no âmbito da avaliação normativa quando se propõem a medir os níveis de controle desenhados por meio de estruturas e processos definidos em normas. Navarro, Costa e Drexler (2010) e Leite (2007), desenvolvendo metodologia de avaliação em serviços de saúde baseada em informações da Visa, discutem a necessidade de compreensão do risco, que pode estar desprovido da mensuração de causa e efeito, porém, necessariamente relacionado aos mecanismos e às falhas de controle. É o que os autores chamam de risco potencial, como um fator possível na determinação de ocorrência de um agravo à saúde, sem necessariamente descrever o agravo e a sua probabilidade de ocorrência. A falta ou a precariedade de instrumentos de Visa que forneçam informações úteis para o diagnóstico da situação sanitária e a magnitude do risco envolvido em serviços de hemoterapia contribui para um processo desqualificado de tomada de decisão (LUCCHESE, 2001).

Nesse contexto, a Agência Nacional de Vigilância Sanitária (Anvisa) elaborou um Método de Avaliação de Riscos Potenciais em Serviços de Hemoterapia (MARPSH), descrito por Silva Júnior e Rattner (2014), que tem sido adotado pelas Visa no seu processo de gerenciamento de riscos em sangue no Brasil. O objetivo deste artigo é descrever o perfil sanitário dos serviços de hemoterapia avaliados durante as inspeções sanitárias nos anos de 2011 e 2012, com a utilização do MARPSH.

\section{Método}

Trata-se de estudo descritivo do perfil sanitário dos serviços de hemoterapia brasileiros, avaliados nos anos de 2011 e 2012 por inspetores de Visa, quando aplicado o MARPSH, cujas planilhas se encontram arquivadas na Anvisa.

\section{Objeto de estudo}

Os serviços de hemoterapia avaliados pela Visa nos anos de 2011 e 2012 foram o objeto deste estudo. Para a caracterização dos serviços, foi utilizada a base de dados do Sistema de Gerenciamento de Cadastros de Serviços de Hemoterapia (Hemocad), gerenciado pela Anvisa, que é o cadastro oficial de Serviços de Hemoterapia ( $\mathrm{SH}$ ) no Brasil. Esse sistema informatizado permite à Visa local a atualização dos dados dos serviços, via sistema hipertextual, com operação pela internet. Devido às variações periódicas no número de serviços registrados no Hemocad, foram utilizados os dados disponíveis no dia 23 de janeiro de 2013.

As planilhas de inspeção do MARPSH, utilizadas como fontes de dados, foram submetidas à análise de consistência, excluindo-se as que não estavam adequadas. Foram excluídas planilhas referentes a serviços inspecionados em outros anos ou que foram submetidos a duas inspeções em um mesmo ano (reinspeção). Nesse caso, optou-se por utilizar a segunda planilha, por refletir a mais recente situação sanitária do serviço. Também foram excluídas planilhas duplicadas, com erros ou lacunas de preenchimento e sem informações passíveis de tratamento. Os erros relacionados às variáveis - razão social e nome fantasia foram corrigidos com auxílio do banco de dados do Hemocad e do Sistema de Cadastro Nacional de Estabelecimentos de Saúde (CNES), do Ministério da Saúde.

Das 994 planilhas disponíveis em 2011, foram eliminadas 26, permanecendo um total de $968 \mathrm{SH}$ avaliados e disponíveis para este estudo. E das 1.094 referentes a 2012, foram eliminadas 18 planilhas, compondo um conjunto de 1.076. Do total de planilhas válidas do ano de 2011 (968) e 2012 (1.076), foram selecionadas aquelas referentes a serviços de hemoterapia que foram avaliados nos dois anos consecutivos. Dessa forma, o material de pesquisa disponível foi composto 
por 1.120 planilhas resultantes da aplicação do MARPSH, referentes aos 560 serviços de hemoterapia inspecionados pela Visa nos anos de 2011 e 2012 respectivamente, consolidadas e arquivadas na Anvisa.

\section{Sobre o MARPSH}

O MARPSH é um instrumental desenvolvido pela Anvisa, utilizado nas ações de inspeção sanitária em SH. Sistematiza a verificação dos cumprimentos dos requisitos estipulados pela legislação sanitária, sendo uma metodologia de Visa para gerenciamento pró-ativo dos riscos referentes ao ciclo do sangue. $\mathrm{O}$ instrumento utiliza a dimensão do risco potencial em uma modelagem multicritério, que integra em seu mecanismo analítico itens diversificados referentes à estrutura e ao processo dos $\mathrm{SH}$. Com esta ferramenta, cada medida de controle é avaliada segundo a estimativa entre a possibilidade da falha e o seu consequente dano, usando, para tanto, uma tabela ou matriz de priorização de riscos potenciais baseada no roteiro de inspeção sanitária. De acordo com a porcentagem dos itens ou requisitos cumpridos, é definido um indicador denominado Proporção de Controle (PC), que classifica os serviços de hemoterapia em cinco classes de risco potencial: $\mathrm{PC} \geq 95 \%$ - Baixo; $80 \% \leq \mathrm{PC}<95 \%$ - Médio-Baixo; $70 \% \leq \mathrm{PC}<80 \%$ - Médio; $60 \% \leq \mathrm{PC}<70 \%$ - Médio-Alto; e PC $<60 \%$ - Alto.

\section{Processo de coleta das informações do MARPSH}

O fluxo de coleta de informações se inicia na inspeção sanitária: a equipe de Visa aplica o roteiro de inspeção, utilizandose de técnicas de observação, entrevista e análise documental. Os inspetores, ao final do trabalho, avaliam as não conformidades encontradas utilizando o MARPSH. Ao transcrever os dados coletados para a planilha do software Microsoft Office Excel, que compõe o MARPSH, o inspetor dispõe de resultados prontamente calculados, podendo classificar o serviço de acordo com o risco potencial. De posse desses resultados, analisa a porcentagem de não conformidades detectadas e as características dos itens não conformes. A equipe de inspeção e o gestor de Visa local avaliam o mecanismo mais efetivo para as ações fiscalizatórias. O relatório e as condutas decisórias são comunicados ao $\mathrm{SH}$ inspecionado, sendo acordadas as adequações necessárias. $\mathrm{O}$ inspetor então finaliza as informações sobre as decisões tomadas, arquiva os documentos e as planilhas de avaliação do MARPSH nos arquivos da Visa local e envia cópias aos entes do Sistema Nacional de Vigilância Sanitária (SNVS). Na Anvisa, essas planilhas são avaliadas, consolidadas em software Microsoft Office Excel e arquivadas.

\section{Análise dos dados}

Os serviços avaliados foram caracterizados em relação ao quantitativo de serviços cadastrados no Hemocad, com descrição do total de serviços por tipologia, definida pela Resolução da Diretoria Colegiada (RDC) Anvisa $\mathrm{n}^{\circ} 151 / 2001$, por macrorregiões brasileiras e por financiamento. A descrição da situação sanitária dos 560 serviços de hemoterapia selecionados e avaliados, consecutivamente, nos anos de 2011 e 2012 se deu utilizando a classificação de risco do MARPSH por tipologia, por macrorregiões e por financiamento. A descrição quantitativa e qualitativa das não conformidades encontradas durante a inspeção foi organizada de acordo com a divisão de categorias adotada em documento da Organização Mundial de Saúde (OMS), 'Good Manufacturing Practices for Blood Establishments', versão 2011; e do Pharmaceutical Inspection Convention Scheme (PIC/s), 'GMP Guide for Blood Establishments', versão 2007, por meio do software Microsoft Office Excel. Dessa forma, os itens de controle foram 
agrupados por suas características relacionadas às dimensões de avaliação de estrutura (física, de materiais e equipamentos, de recursos humanos, de documentação/registros) e de processo (procedimentos técnicos e gestão da qualidade).

Além dessa categorização, as não conformidades foram estruturadas por setores ou locais relacionados ao ciclo do sangue, como não conformidades de âmbito geral, relacionadas ao doador, ao processamento de sangue e seus componentes, aos testes laboratoriais e ao setor de transfusão sanguínea. Dentre os 471 itens de controle que compõem a matriz avaliativa, foram escolhidos aqueles cujas não conformidades apareceram em mais de $10 \%$ dos serviços, em pelo menos um dos anos avaliados. Assim, foram selecionados 64 itens de controle, que apresentaram algum tipo de não conformidade. As frequências observadas foram organizadas de forma a possibilitar a visualização da diferença percentual entre os itens de controle não conformes nos dois anos avaliados. O estudo foi aprovado pelo Núcleo de Educação, Pesquisa e Conhecimento, seguindo a Política de Segurança da Informação e Comunicações da Anvisa (Portaria 1552, de 12 de novembro de 2012), que estabeleceu as diretrizes para a segurança do manuseio, tratamento, controle e proteção dos dados, informações e conhecimentos produzidos, armazenados ou transmitidos pela Agência.

\section{Resultados}

Do material disponível para estudo, foi possível avaliar, comparativamente, nos dois anos consecutivos (2011 e 2012), 28\% dos serviços cadastrados no Brasil, correspondendo a quase metade dos serviços avaliados por cada ano, separadamente. Analisando por tipo de serviço, a menor porcentagem do quantitativo avaliado em relação aos serviços cadastrados foi $18 \%$, referente à Central de Laboratorial de Doadores de Sangue (CTLD). Na região Centro-Oeste, 19 serviços foram avaliados, correspondendo a $11 \%$ em relação ao Hemocad, sendo esta a menor representação por macrorregiões encontradas neste estudo.

Da mesma forma, por tipo de financiamento, os serviços de natureza privada conveniada ao Sistema Único de Saúde (SUS) representaram $25 \%$ dos cadastrados no Hemocad, sendo essa a menor representação da categoria.

A tabela 1 apresenta o quantitativo dos serviços disponíveis para análise, para cada um desses dois anos (2011 e 2012), e os que foram avaliados nos dois anos consecutivos. A tabela 2 apresenta a distribuição do risco potencial nos 560 serviços de hemoterapia avaliados, consecutivamente, nos anos de 2011 e 2012, por tipologia de serviços, por macrorregiões geográficas do Brasil e por natureza de financiamento. 
Tabela 1. Distribuição (no e \%) de serviços de hemoterapia avaliados nos anos de 2011 e 2012, em comparação àqueles avaliados nos dois anos consecutivos, por tipologia de serviço, por macrorregiões brasileiras e por tipo de financiamento. Brasil, 2011 e 2012

\begin{tabular}{|c|c|c|c|c|c|c|c|}
\hline \multirow{2}{*}{$\begin{array}{c}\text { Serviços de } \\
\text { Hemoterapia }\end{array}$} & \multirow{2}{*}{$\begin{array}{l}\text { Hemocad } \\
n^{n} \stackrel{0}{ }\end{array}$} & \multicolumn{2}{|c|}{ Avaliados 2001} & \multicolumn{2}{|c|}{ Avaliados 2012} & \multicolumn{2}{|c|}{ Avaliados 11/12 } \\
\hline & & $\mathrm{n}^{\circ}$ & $\%$ & $\mathrm{n}-$ & $\%$ & $\mathrm{n}-$ & $\%$ \\
\hline Total & 2014 & 968 & 48 & 1076 & 53 & 560 & 28 \\
\hline \multicolumn{8}{|l|}{ Tipologia } \\
\hline UC & 14 & 12 & 86 & 11 & 79 & 3 & 21 \\
\hline AT & 1453 & 689 & 47 & 785 & 54 & 406 & 28 \\
\hline UCT & 148 & 62 & 42 & 72 & 49 & 29 & 20 \\
\hline CTLD & 11 & 2 & 18 & 9 & 82 & 2 & 18 \\
\hline $\mathrm{NH}$ & 290 & 125 & 43 & 134 & 46 & 77 & 26,5 \\
\hline$H R$ & 65 & 58 & 89 & 45 & 69 & 30 & 46 \\
\hline $\mathrm{HC}$ & 27 & 20 & 74 & 20 & 74 & 13 & 48 \\
\hline $\mathrm{NI}$ & 6 & - & - & - & - & - & - \\
\hline \multicolumn{8}{|l|}{ Macrorregiões } \\
\hline Centro-Oeste & 168 & 41 & 24 & 59 & 25 & 19 & 11 \\
\hline Nordeste & 358 & 217 & 61 & 212 & 59 & 122 & 34 \\
\hline Norte & 164 & 48 & 29 & 60 & 37 & 25 & 15 \\
\hline Sudeste & 897 & 477 & 53 & 586 & 65 & 285 & 32 \\
\hline Sul & 427 & 185 & 43 & 159 & 37 & 109 & 25 \\
\hline \multicolumn{8}{|l|}{ Financiamento } \\
\hline Privado & 408 & 215 & 53 & 247 & 60,5 & 123 & 30 \\
\hline Privado/SUS** & 725 & 357 & 49 & 307 & 42 & 179 & 25 \\
\hline Público (SUS) & 881 & 396 & 45 & 522 & 59 & 258 & 29 \\
\hline \multicolumn{8}{|c|}{ Classificação Risco } \\
\hline Baixo & - & 187 & 19 & 255 & 24 & - & - \\
\hline Médio-Baixo & - & 385 & 40 & 467 & 43 & - & - \\
\hline Médio & - & 187 & 19 & 182 & 17 & - & - \\
\hline Médio-Alto & - & 114 & 12 & 100 & 9 & - & - \\
\hline Alto & - & 95 & 10 & 72 & 7 & - & - \\
\hline
\end{tabular}

Fonte: Elaboração própria.

*UC - Unidade de Coleta; AT - Agência Transfusional; UCT - Unidade de Coleta e Transfusão; CTLD - Central de Triagem Laboratorial de Doadores; NH - Núcleo de Hemoterapia; HR - Hemocentro Regional; HC - Hemocentro Coordenador; NI - Não Informado.

**SUS - Sistema Único de Saúde. 
Tabela 2. Distribuição (no e \%) dos 560 serviços de hemoterapia avaliados por classificação de risco potencial, por tipologia de serviços de hemoterapia, por macrorregiões geográficas brasileiras e por natureza do financiamento. Brasil, 2011 e 2012

Risco Potencial no (\%)

\begin{tabular}{|c|c|c|c|c|c|c|c|c|c|}
\hline Baixo & & Médio-Ba & & Médio & & Médio-Al & & Alto & \\
\hline $\begin{array}{c}2011 \\
\text { no (\%) }\end{array}$ & $\begin{array}{c}2012 \\
\text { no }(\%)\end{array}$ & $\begin{array}{c}2011 \\
\text { no (\%) }\end{array}$ & $\begin{array}{c}2012 \\
\text { n- (\%) }\end{array}$ & $\begin{array}{c}2011 \\
\text { n- (\%) }\end{array}$ & $\begin{array}{c}2012 \\
\text { n- (\%) }\end{array}$ & $\begin{array}{c}2011 \\
\text { no }(\%)\end{array}$ & $\begin{array}{c}2012 \\
\text { n- (\%) }\end{array}$ & $\begin{array}{c}2011 \\
\text { no (\%) }\end{array}$ & $\begin{array}{c}2012 \\
\text { no (\%) }\end{array}$ \\
\hline
\end{tabular}

\begin{tabular}{|c|c|c|c|c|c|c|c|c|c|c|}
\hline Tipologia* (nº) & & & & & & & & & & \\
\hline UC (3) & $2(67)$ & $2(67)$ & $1(33)$ & $1(33)$ & - & - & - & - & - & - \\
\hline AT (406) & $67(17)$ & $99(24)$ & $154(38)$ & $172(43)$ & $87(21)$ & $73(18)$ & $52(13)$ & $44(11)$ & $46(12)$ & $18(4)$ \\
\hline UCT (29) & $6(21)$ & $9(31)$ & $12(41)$ & $11(38)$ & $4(14)$ & $5(17)$ & $4(13)$ & $3(10)$ & $3(10)$ & $1(3)$ \\
\hline CTLD (2) & $1(50)$ & - & $1(50)$ & $2(100)$ & - & - & - & - & - & - \\
\hline $\mathrm{NH}(77)$ & $23(30)$ & 30 (39) & $28(49)$ & $32(41)$ & $6(8)$ & $9(12)$ & $6(8)$ & $4(5)$ & $4(5)$ & $2(3)$ \\
\hline HR (30) & $4(13)$ & $9(30)$ & $16(54)$ & $14(47)$ & $7(23)$ & $7(23)$ & $2(7)$ & - & $1(3)$ & - \\
\hline HC (13) & $2(15)$ & $2(15)$ & $5(38)$ & $10(78)$ & $3(23)$ & $1(8)$ & $2(15)$ & - & $1(8)$ & - \\
\hline
\end{tabular}

Macrorregiões(nㅇ)

\begin{tabular}{lcccccccccc}
\hline Centro-Oeste (19) & $6(32)$ & $5(25)$ & $6(32)$ & $8(42)$ & $3(16)$ & $4(22)$ & $1(5)$ & $2(10)$ & $3(16)$ & - \\
Nordeste (122) & $14(12)$ & $17(13)$ & $42(34)$ & $52(45)$ & $37(30)$ & $29(24)$ & $14(12)$ & $17(13)$ & $15(12)$ & $7(5)$ \\
Norte (25) & - & - & $7(28)$ & $9(36)$ & $7(28)$ & $6(24)$ & $4(16)$ & $9(36)$ & $7(28)$ & $1(4)$ \\
Sudeste (285) & $60(21)$ & $95(33)$ & $120(42)$ & $129(45)$ & $45(16)$ & $38(13)$ & $37(13)$ & $13(5)$ & $23(8)$ & $10(4)$ \\
Sul (109) & $25(23)$ & $36(33)$ & $51(47)$ & $42(39)$ & $16(15)$ & $18(17)$ & $10(9)$ & $10(9)$ & $7(6)$ & $3(3)$ \\
\hline Financiamento(no) & & & & & & & & & \\
\hline Privado (123) & $46(37)$ & $52(42)$ & $46(37)$ & $52(42)$ & $19(15)$ & $11(9)$ & $6(5)$ & $7(6)$ & $6(5)$ & $1(1)$ \\
Privado/SUS** (179) & $30(17)$ & $40(22)$ & $82(46)$ & $94(52)$ & $35(19)$ & $29(16)$ & $20(11)$ & $8(5)$ & $12(7)$ & $8(5)$ \\
Público (258) & $29(11)$ & $53(21)$ & $98(38)$ & $97(37)$ & $54(21)$ & $58(22)$ & $40(16)$ & $38(15)$ & $37(14)$ & $12(5)$ \\
\hline
\end{tabular}

Fonte: Elaboração própria.

*UC - Unidade de Coleta; AT - Agência Transfusional; UCT - Unidade de Coleta e Transfusão; CTLD - Central de Triagem Laboratorial de Doadores; NH - Núcleo de Hemoterapia; HR - Hemocentro Regional; HC - Hemocentro Coordenador

**SUS - Sistema Único de Saúde.

Em relação à distribuição por tipologia, apesar de, em 2012, apresentarem o maior percentual de serviços com Alto risco (A) e Médio-Alto risco (MA), as Agências Transfusionais (AT) tiveram uma redução de serviços críticos - A (-8\%), MA (-2\%) e Médio risco (M) (-3\%) -, e aumento de serviços com classificação de Médio-Baixo risco (MB) (+5\%) e Baixo risco (B) (+7\%), ou seja, serviços com mais de $80 \%$ na pontuação referente aos itens de controle cumpridos. Observa-se que, de 2011 para 2012, duas 
Unidades de Coleta e Transfusão (UCT) saíram do A e uma do MA, porém, quatro UCT se apresentaram em situação insatisfatória no ano de 2012 - três de MA e uma de A. Entre os Núcleos de Hemoterapia $(\mathrm{NH})$ avaliados, dois apresentaram-se, em 2012, com A, significando problemas críticos e menos de $60 \%$ na pontuação referente aos requisitos regulatórios cumpridos. Também se observa queda no número de serviços de A e MA, porém, com um aumento de $4 \%$ no número de serviços de $\mathrm{M}$, aumentando de seis para nove serviços nesta classificação. Os Hemocentros Coordenadores (HC) e os Hemocentros Regionais (HR) apresentaram eliminação de serviços com A e MA, e as maiores porcentagens de serviços com mais de $80 \%$ dos itens de controle cumpridos, sendo os HC com aproximadamente 12 (93\%) serviços classificados como B ou MB e os HR em torno de 23 (77\%), no ano de 2012. Ressalta-se que os HR apresentaram, também no ano de 2012, sete serviços classificados como M, significando uma pontuação entre $80 \%$ e $70 \%$, referente ao cumprimento da legislação.

Comparando o risco potencial observado por regiões do Brasil, nota-se que na região Sudeste houve diminuição nas proporções de riscos críticos entre as duas avaliações (-3\% M, $-8 \%$ MA e $-4 \%$ A) e aumento do número de serviços com $\mathrm{MB}(+3 \%)$ e $\mathrm{B}$ $(+12 \%)$. Na região Norte houve uma diminuição de seis serviços de A, entre 2011 e 2012, e um aumento de cinco serviços de MA, podendo significar um deslocamento de Alto para Médio-Alto. A região Nordeste teve um aumento de três serviços de B e dez de $\mathrm{MB}$, e diminuição de oito serviços de $\mathrm{M}$ e oito de A; porém, houve um aumento de três serviços classificados em MA. Os resultados da região Centro-Oeste são bem diferenciados, com nenhum de A, no ano de 2012; porém, com um aumento em um serviço nas classificações MA e M, com diminuição de um serviço de B e elevação de dois serviços de MB. A região Sul, apesar da redução no número de serviços de $\mathrm{A}$, de 7 para 3 e aumento nos de B, de 25 para 36 , apresentou um aumento de 2 serviços em $\mathrm{M}$ e queda de 8 serviços de MB. Os serviços privados apresentaram, no ano de 2012, 104 (84\%) classificados como B e MB, com uma queda de $8(-6 \%)$ serviços com $\mathrm{M}$ e $5(-4 \%)$ de serviços com A, no intervalo de 2011 e 2012.

Os serviços de hemoterapia privados/ SUS, em 2012, se apresentaram com 74\% classificados em B e MB, e com quedas em todas as classificações críticas (MA e A). Os serviços públicos apresentaram, em 2012, 12 serviços em A, com uma redução, em relação a 2011, de 24 (-9\%) serviços nesta classificação. Nota-se também que serviços públicos aumentaram em $24(+10 \%)$, que alcançaram a classificação de $\mathrm{B}$.

Um panorama geral da situação sanitária dos 560 serviços de hemoterapia avaliados mostra que aproximadamente 59\% desses estavam classificados em B e MB, em 2011, e, no ano seguinte, cerca de $70 \%$ se situavam nessas classificações. No caso das classificações mais críticas, MA e A, esse quadro se inverteu, com aproximadamente $22 \%$ dos serviços classificados nesse extrato, em 2011, sendo reduzido, em 2012, para 13\%. Houve um acréscimo de quase $9 \%$, de 2011 a 2012 , no número de serviços classificados como $\mathrm{B}$, e uma queda de aproximadamente $6 \% \mathrm{em}$ serviços de A. No ano de 2012, nota-se ainda um percentual de cerca $13 \%$ de $\mathrm{SH}$ avaliados, neste estudo, com classificações consideradas críticas (MA e A).

O gráfico 1 apresenta a classificação geral, segundo risco potencial dos $\mathrm{SH}$ avaliados neste estudo. O gráfico 2, por sua vez, apresenta o deslocamento do percentual de serviços avaliados nos dois anos consecutivos, de acordo com a dispersão das cinco possibilidades de classificações de risco definidas pelo MARPSH. Percebe-se um nítido deslocamento do conjunto de $\mathrm{SH}$ para os vértices de $\mathrm{MB}$ e $\mathrm{B}$, e um leve afastamento da área de A e MA. 
Gráfico 1. Distribuição do risco potencial em 560 serviços de hemoterapia. Brasil, 2011 e 2012

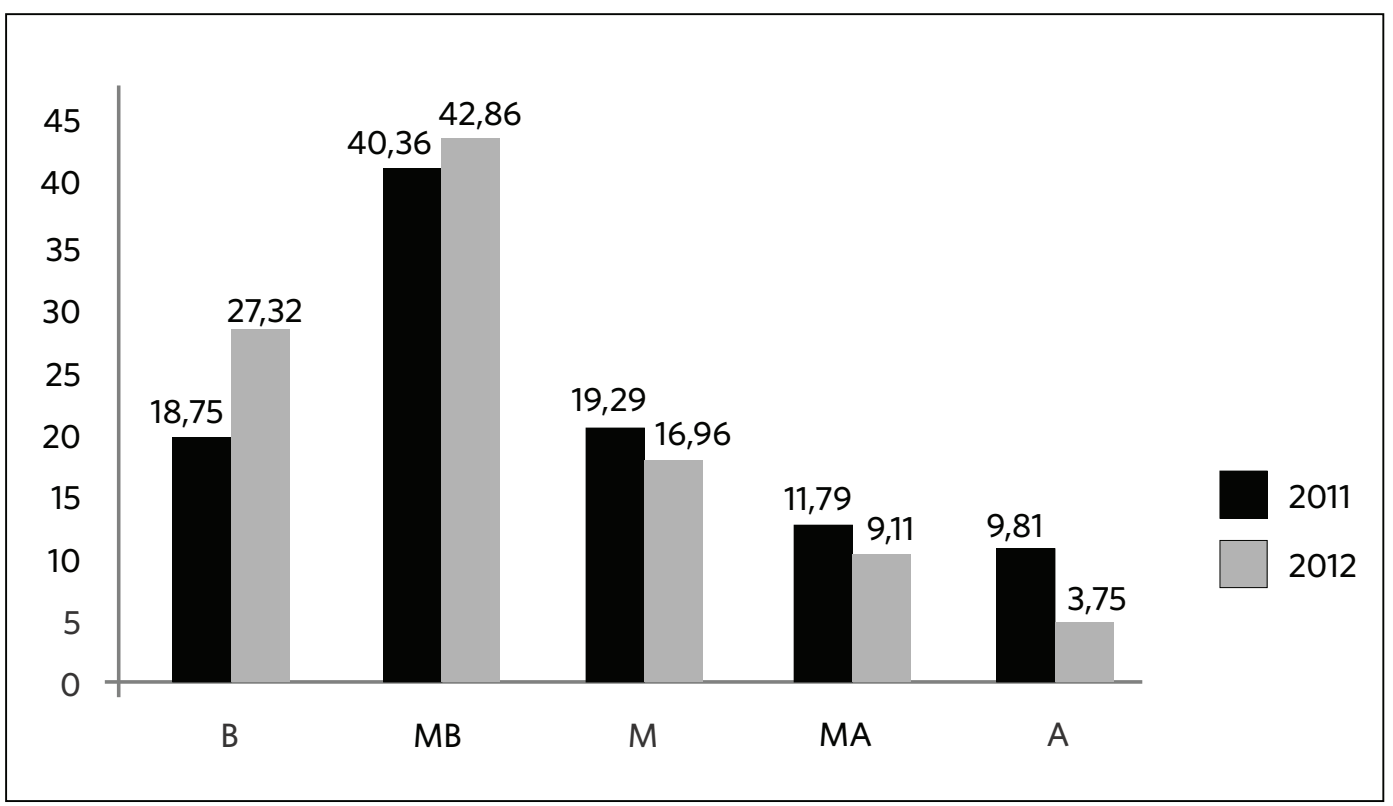

Fonte: Elaboração própria.

Risco potencial: B - Baixo; MB - Médio-Baixo; M - Médio; MA - Médio-Alto; A - Alto.

Gráfico 2. Distribuição e dispersão do risco potencial (\%) em 560 serviços de hemoterapia. Brasil, 2011 e 2012

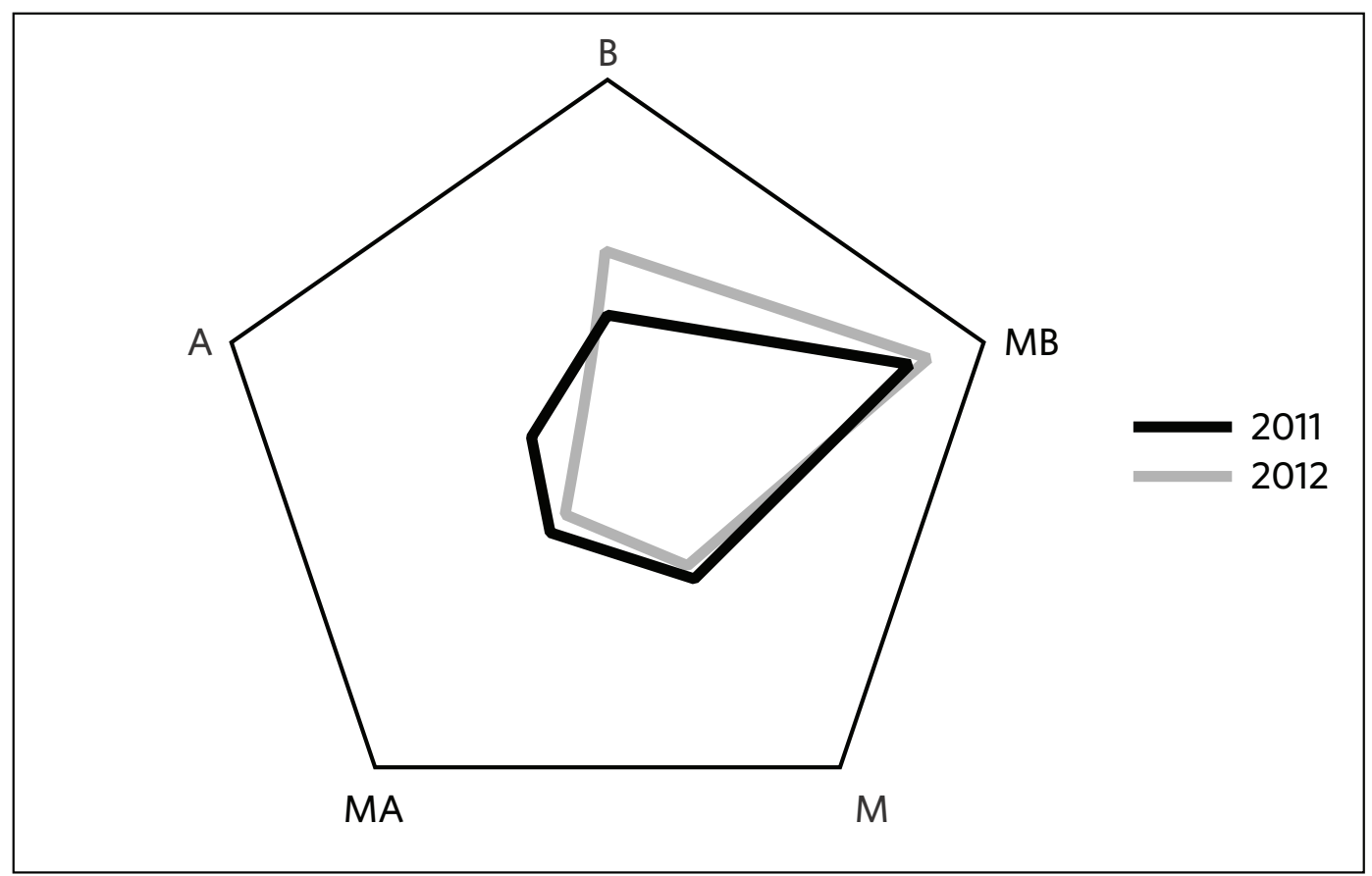

Fonte: Elaboração própria.

Risco potencial: B - Baixo; MB - Médio-Baixo; M - Médio; MA - Médio-Alto; A - Alto. 
No quadro 1 são apresentados os itens de controle com maior frequência de não conformidades detectadas, referentes aos requisitos sanitários. Os itens são apresentados em seu agrupamento categórico, setor do serviço de hemoterapia envolvido, tipo de item avaliativo (estrutura e processo), frequência dos erros encontrados nos dois anos e diferença percentual observada. Dos 64 itens de controle com não conformidades mais frequentes em $2011 \mathrm{e}$ 2012, 19 (29,7\%) referem-se a procedimentos de garantia da qualidade, 13 (20,3\%) estão relacionados à documentação e sistemas de registros, $10(15,6 \%)$ a materiais e equipamentos, 9 (14\%) a recursos humanos, $7(11 \%)$ a procedimentos técnicos e $6(9,4 \%)$ estão relacionados à estrutura física. De acordo com os setores dos $\mathrm{SH}$, nota-se que $32(50 \%)$ referem-se a não conformidades de âmbito geral, considerados itens de controle transversais, com requisitos que abrangem todos os setores, como, por exemplo, responsabilidade técnica, saúde do trabalhador, estrutura física, biossegurança, manejo de resíduos, gestão de equipamentos, gestão da qualidade e gestão de documentação. Outro setor com frequentes não conformidades é o da transfusão, com 17 (27\%) não conformidades apontadas, destacando, nesta área, os procedimentos dos testes pré-transfusionais. $\mathrm{O}$ setor de processamento, armazenamento e distribuição de hemocomponentes foi responsável por sete (11\%) das não conformidades detectadas; o ciclo do doador, que compreende captação e registro de doadores, triagem clínica, coleta de sangue e cuidados com o doador, apresentou seis (9\%) não conformidades; e, por fim, dois (3\%) dos problemas mais frequentes encontrados nos laboratórios de triagem de doadores, concentrando maiores falhas na área de testes imuno-hematológicos. Do total de não conformidades, 59,4\% (38) descrevem itens avaliativos relacionados à dimensão da estrutura e 40,6\% (26) correspondem a itens da dimensão de avaliação de processos. Dos itens que apresentaram maiores diferenciações de um ano para outro, destacam-se $15 \%$ de redução nas não conformidades relacionadas a programas de capacitação de recursos humanos, $12 \%$ de queda relacionada aos problemas em registros dos receptores de sangue e falta de procedimentos operacionais para o setor de transfusão, $11 \%$ de redução nas não conformidades relacionadas à definição de planos de contingência para casos de corte de energia elétrica e mais de $10 \%$ de redução de não conformidades referentes à requisição médica de transfusão, à manutenção e qualificação de equipamentos, à atribuição e definição de responsabilidades setoriais, entre outros. Apenas o item referente à investigação de soroconversão obteve um aumento de não conformidades, entre 2011 e 2012 . 
Quadro 1. Distribuição percentual dos itens de controle relacionados às não conformidades detectadas nas inspeções sanitárias em serviços de hemoterapia. Brasil, 2011 e 2012

\begin{tabular}{|c|c|c|c|c|c|}
\hline $\begin{array}{l}\text { Categoria } \\
\text { (no de itens) }\end{array}$ & Setor & Item de controle - Avaliação de estrutura & $\begin{array}{l}\% \mathrm{NCSH}^{\star} \\
(2011)\end{array}$ & $\begin{array}{l}\% \mathrm{NCSH}^{\star} \\
(2011)\end{array}$ & Dif \%*夫 \\
\hline \multirow{6}{*}{$\begin{array}{l}\text { Estrutura Física } \\
\text { (6) }\end{array}$} & Geral & Planta arquitetônica e edificação correspondente & 44 & 39 & -5 \\
\hline & Geral & Proteção contra entrada de insetos e roedores & 22 & 17 & -5 \\
\hline & Geral & Bom estado de conservação e higienização & 20 & 13 & -7 \\
\hline & Geral & Revestimento de pisos, paredes e tetos & 13 & 11 & -2 \\
\hline & Geral & Setores sinalizados conforme biossegurança & 26 & 20 & -6 \\
\hline & Transfusão & Área física de Agência Transfusional (AT) & 23 & 19 & -4 \\
\hline \multirow{10}{*}{$\begin{array}{l}\text { Materiais e } \\
\text { Equipamentos } \\
\text { (10) }\end{array}$} & Geral & Equipamentos qualificados & 44 & 40 & -4 \\
\hline & Geral & Avaliação de equipamentos antes do uso & 33 & 25 & -8 \\
\hline & Geral & Plano de contingência para cortes de energia elétrica & 50 & 39 & -11 \\
\hline & Geral & Sistema emergencial de energia elétrica & 12 & 10 & -2 \\
\hline & Geral & Calibração ou aferição de equipamentos & 43 & 39 & -4 \\
\hline & Geral & Manutenção preventiva dos equipamentos & 36 & 29 & -7 \\
\hline & Laboratório & $\begin{array}{l}\text { Pipetas e termômetros no laboratório de imuno-hematologia } \\
\text { do doador calibrados }\end{array}$ & 30 & 22 & -8 \\
\hline & $\begin{array}{l}\text { Processamento } \\
\text { de sangue }\end{array}$ & $\begin{array}{l}\text { Equipamentos do laboratório de controle de qualidade de } \\
\text { hemocomponentes com manutenção }\end{array}$ & 25 & 23 & -2 \\
\hline & $\begin{array}{l}\text { Processamento } \\
\text { de sangue }\end{array}$ & Equipamentos com manutenção/calibração & 20 & 10 & -10 \\
\hline & Transfusão & $\begin{array}{l}\text { Refrigeradores e congeladores para conservação de hemo- } \\
\text { componentes em AT }\end{array}$ & 21 & 14 & -7 \\
\hline \multirow{9}{*}{$\begin{array}{l}\text { Recursos } \\
\text { Humanos (9) }\end{array}$} & Geral & Programa de capacitação de recursos humanos & 52 & 37 & -15 \\
\hline & Geral & $\begin{array}{l}\text { Treinamento de pessoal em biossegurança e manejo de } \\
\text { resíduos }\end{array}$ & 42 & 35 & -7 \\
\hline & Geral & Programa de controle médico de saúde ocupacional & 33 & 27 & -6 \\
\hline & Geral & Médico responsável técnico & 10 & 6 & -4 \\
\hline & Geral & $\begin{array}{l}\text { Disponibilização e uso de Equipamento de Proteção Indivi- } \\
\text { dual (EPI) e Equipamento de Proteção Coletiva (EPC) ade- } \\
\text { quados }\end{array}$ & 12 & 6 & -6 \\
\hline & Geral & $\begin{array}{l}\text { Treinamento de pessoal quando ocorrem mudanças nos } \\
\text { procedimentos e processos }\end{array}$ & 35 & 31 & -4 \\
\hline & Geral & $\begin{array}{l}\text { Imunização contra hepatite B para os trabalhadores submeti- } \\
\text { dos a risco biológico }\end{array}$ & 16 & 10 & -6 \\
\hline & Doador & $\begin{array}{l}\text { Treinamento de pessoal para atendimento ao doador em } \\
\text { situações de emergências }\end{array}$ & 36 & 36 & 0 \\
\hline & Doador & Assistência de médico durante período de coleta de sangue & 16 & 14 & -2 \\
\hline
\end{tabular}


Quadro 1. (cont.)

Documentos e Registros

\section{Geral}

Geral

Geral

Geral

Doador

Processamento

de sangue

Processamento

de sangue

Processamento

de sangue

Transfusão

Transfusão

Transfusão

Transfusão

Transfusão

Doador

Processamento

de sangue

Transfusão

Procedimentos
Técnicos

(7)

Transfusão

Transfusão

Transfusão

Transfusão

Geral

Geral

Geral

Qualidade

(19)
Plano de gerenciamento de resíduos de serviços de saúde

Protocolos de controle das indicações e do descarte de hemocomponentes

Rastreabilidade dos processos e produtos

Plano de contingência para casos de falhas do sistema informatizado

Procedimentos padronizados para cadastro de doadores

Procedimentos padronizados para controle de qualidade de

hemocomponentes

Documento formalizado para distribuição de hemocomponentes (contratualização)

Procedimentos padronizados para reintegração de hemocomponentes

Protocolo para liberação de sangue incompatível

Requisição de transfusão

Etiqueta de liberação da bolsa de sangue para transfusão com dados completos

Ficha do receptor com dados completos

Procedimentos padronizados em AT

Atendimento de reações adversas ao doador

Congelamento de plasma fresco congelado

Comitê transfusional funcionando

Detecção, tratamento e prevenção de reações transfusionais

Identificação completa do tubo de amostra de sangue do receptor (testes pré-transfusionais)

Resolução de discrepância nos testes laboratoriais imuno-

-hematológicos do receptor (pré-transfusional)

Liberação de hemácias em situações de urgência/emergência

Validação de processos críticos

Devolução de produtos não conformes

Organograma com responsabilidades definidas

Mecanismos para a avaliação de reclamações de clientes

Tratamento de não conformidades

Geral

Geral

Geral
Qualificação dos fornecedores de materiais e equipamentos
Avaliação sistemática, quando da alteração dos processos

\section{7}

35

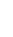

12

19

33

28

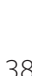

38

36

20

24

39

26

12

39

28

20

18

22

48

43

46

26

43

36

36

\section{5}

30

$-5$

(2)

7

7

16

$-5$

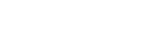

17

17

17

$-6$

(2)

$22-6$

(2)

$27-11$

26

$26-10$

15

$-5$

$12-12$

$\begin{array}{ll}27 & -12\end{array}$

$26 \quad 24$

$8-4$

$\begin{array}{lll}39 & 32 & -7\end{array}$

$23-5$

$15-5$

$13-5$

$\begin{array}{lll}22 & 16 & -6 \\ 48 & 45 & -3 \\ 43 & 28 & -5 \\ 46 & 34 & -12 \\ 26 & 22 & -4 \\ 43 & 37 & -6 \\ 36 & 32 & -4 \\ 36 & 30 & -6\end{array}$

$\begin{array}{lll}22 & 16 & -6 \\ 48 & 45 & -3 \\ 43 & 28 & -5 \\ 46 & 34 & -12 \\ 26 & 22 & -4 \\ 43 & 37 & -6 \\ 36 & 32 & -4 \\ 36 & 30 & -6\end{array}$




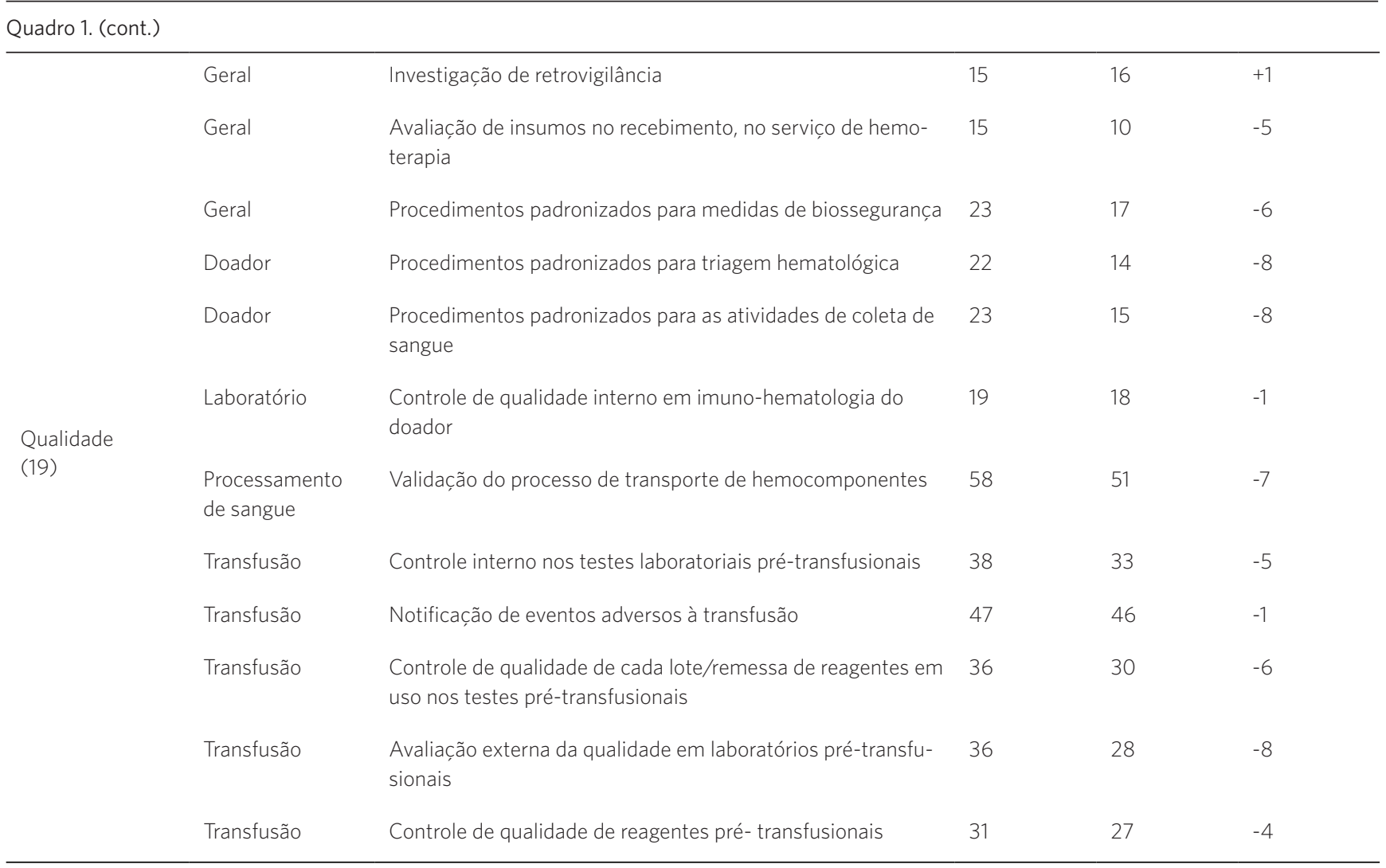

Fonte: Elaboração própria.

*NC SH: Não Conformes em Serviços de Hemoterapia.

**Diferença de porcentagens de não conformidades, entre os anos 2011 e 2012.

\section{Discussão}

Os resultados expostos nos gráficos 1 e 2 mostram que os serviços avaliados nesse intervalo de tempo avançaram na adequação à legislação e, consequentemente, fortaleceram os seus sistemas de controle de riscos. Além disso, constatou-se que a maioria dos serviços brasileiros (70\%, em 2012) ficou classificada como B e MB, significando um percentual de mais de $80 \%$ na pontuação referente aos requisitos regulatórios cumpridos, de acordo com a classificação definida no MARPSH.

No gráfico 2, que desenha o pentágono da distribuição de serviços no espaço de risco avaliado, percebe-se um nítido deslocamento do conjunto de serviços para os vértices de $\mathrm{MB}$ e $\mathrm{B}$, e um leve afastamento da área de A e MA. Esta representação gráfica traz a percepção de movimento apropriado para entender o comportamento dos riscos em serviços complexos e a necessidade de monitoramento permanente dos mecanismos de controle. A dinâmica das atividades produtivas e assistenciais desenvolvidas no ciclo do sangue e a natureza dos controles que envolvem pessoas e máquinas explicam a possibilidade de flutuação e variações nos níveis de riscos, exigindo mecanismos de alta vigilância por parte dos próprios serviços, em seus sistemas de garantia de qualidade, nas 
avaliações externas - como as da vigilância sanitária -, de acreditadores e de outros avaliadores.

No entanto, apesar dos avanços observados entre os dois anos, um resultado que merece destaque, no estudo, é que, em 2012, 73 (12\%) SH avaliados apresentaram situações críticas (MA e A). Situação sanitária desta ordem demanda a atenção dos gestores das políticas públicas nacionais e locais, dos próprios serviços e do SNVS, na perspectiva de reversão deste perfil sanitário. Identificase, assim, um grande potencial dos serviços de hemoterapia para a adequação de suas não conformidades, considerando que, em um ano de avaliação da Visa, houve um aumento de cerca de $11 \%$ no quantitativo de serviços classificados em situação satisfatória (B e MB). A descrição da situação de risco dos SH, por macrorregiões do País, definida por meio do MARPSH, possibilitou o mapeamento dos riscos no território, apresentando a utilidade do método na visualização do perfil sanitário regionalizado.

Como a unidade de avaliação foi a macrorregião, muitas oscilações observadas puderam ser reflexo de avanços pontuais em determinados serviços e de retrocessos em outros. Esse fato evidencia uma característica do MARPSH, de detectar sinalizadores de controle considerados críticos, que, no cumprimento ou não de determinados itens específicos, podem ocasionar mudanças na classificação geral do serviço. Os resultados agregados sinalizam situações gerais da população estudada, com identificação dos focos de riscos potenciais que podem orientar ações de Visa por macrorregiões ou por unidades federativas, com subsídio de informações para o direcionamento das políticas públicas de sangue com foco regional. No entanto, adquire maior especificidade quando a análise discrimina por unidade de serviço de hemoterapia. O resultado encontrado na região Norte apresenta outra característica importante na análise dos resultados do MARPSH, que é o deslocamento dos serviços nas diversas classificações de risco definidas, mediante o cumprimento, ou não, de itens de controle. Foi observado que seis serviços deixaram a classificação de $\mathrm{A}$, e cinco serviços entraram na classificação MA, o que pode ter sido ocasionado pelo deslocamento de uma classe para a outra, representando melhorias, ainda que insuficientes, nos sistemas de controle. Esta situação indica a necessidade de adequações nos processos e estruturas, e a intensificação dos mecanismos fiscalizatórios, na busca pela saída dessa zona crítica de risco, uma vez que a região Norte demonstrou ter potencial de avanços, pois apresentou dois serviços que conseguiram a classificação de MB.

Outro recorte deste estudo se deu por tipologia de serviços. As AT apresentaram, em 2012, 15 serviços com A e MA, sendo o maior número em relação à tipologia de serviços hemoterápicos. Desta forma, estes resultados são importantes no direcionamento de ações específicas no setor, uma vez que, nesses serviços, acontecem os preparativos para a realização da transfusão, com testes de compatibilidade entre doador e receptor, e dispensação de hemocomponentes para determinado paciente. É nas AT que mais acontecem erros responsáveis por eventos adversos graves à transfusão, incluindo o óbito (VUK ET AL., 2012). Os HC, os HR e os NH apresentaram os melhores resultados, com a maioria dos serviços classificados como B e MB, o que reflete um cenário favorável, uma vez que são serviços estratégicos, por serem referências técnicas em suas regiões, pois desenvolvem, em geral, a maioria das atividades do ciclo do sangue, tornando-se multiplicadores de boas práticas deste ciclo. Nessa perspectiva, chamam a atenção os resultados dos $\mathrm{NH}$, com dois serviços, em 2012, em A, significando problemas críticos, com menos de $60 \%$ dos requisitos regulatórios cumpridos, além de quatro serviços em MA. Esta constatação sugere a necessidade de análise individualizada, com identificação dos problemas específicos, por cada 
NH, para a proposição de mecanismos de melhorias. Ressalta-se que os HR, apesar de terem avançado em melhorias importantes, eliminando serviços de A e MA risco e concentrando mais de $76 \%$ dos serviços em situações satisfatórias, ainda apresenta um quantitativo preocupante de sete (23\%) serviços classificados como $\mathrm{M}$ risco, significando um alcance em torno de $70 \%$ na pontuação relacionada a itens regulatórios cumpridos. Os resultados apresentados na tabela 2 mostram que os serviços privados apresentaram os melhores resultados no que se refere ao cumprimento da legislação técnica vigente, com os menores percentuais de serviços classificados como de situação crítica, no ano de 2012, comportamento similar exibido pelos serviços privados/SUS.

Os serviços públicos apresentaram, em 2012, dez serviços classificados como A e MA, porém, com uma redução da ordem de $9 \%$ de A e uma melhora de $9,5 \%$ no aumento de serviços de B, considerando o existente no ano de 2011. Estes dados demonstram o potencial dos serviços públicos para avançar na qualidade em saúde, em que pesem as dificuldades da gestão do setor. Ainda que se reconheça que há limitações neste estudo, parece lícito discutir as disparidades encontradas referentes ao risco sanitário de serviços de hemoterapia por tipo de financiamento. No campo da vigilância sanitária de produtos e processos, não há diferenciação do que deve ser disponibilizado no âmbito público ou privado; o objetivo deve ser único na direção da qualidade, segurança e eficiência dos resultados. Discussão similar ocorreu na I Conferência Nacional de Vigilância Sanitária, em 2001, sobre o tratamento desigual no processo fiscalizatório de Visa entre o setor público e o privado (ANVISA, 2001). A mais rápida resposta dos serviços privados às intervenções de Visa, aliada às dificuldades no emprego dos dispositivos fiscais de intervenções sanitárias, devido às interferências de interesses políticos, podem pontuar sobre este cenário desigual nas ações de Visa e, consequentemente, nos resultados de controle dos serviços públicos e privados. Em ambos os subsistemas inseridos no sistema de saúde brasileiro, foram detectadas dificuldades e fortalezas que precisam ser levadas em conta na análise dos resultados deste estudo. Segundo Victora et al. (2011), as complexas dimensões das relações de serviços públicos e privados na saúde brasileira estão ainda por ser adequadamente enfrentadas. No entanto, pode-se inferir, pelos resultados observados, que a rápida resposta do setor privado às exigências regulatórias é facilitada pela incorporação de tecnologias gerenciais, de controle e de segurança. A deficiência na gestão administrativa, bem como o descaso dos profissionais dos serviços de saúde no setor público, é uma das linhas explicativas para a ineficiência da incorporação de mecanismos de controle de riscos no SUS. Note-se que mais de $58 \%$ dos serviços públicos foram classificados em situações favoráveis, o que abre a possibilidade de que outros serviços dessa natureza avancem na direção do cumprimento da legislação vigente.

Um dos importantes atributos do MARPSH, explorado neste estudo, é a possibilidade de identificar problemas específicos dos serviços avaliados, conforme mostra o quadro 1. Essa abordagem torna-se importante para a Visa, na perspectiva da proposição de medidas de correção dos itens pontuais e por cada parte do processo do ciclo do sangue. Agências reguladoras internacionais na área de sangue (EUROPEAN UNION, 2003) têm identificado os mesmos problemas detectados, com o estabelecimento de estratégias de indução regulatória em $\mathrm{SH}$ baseadas em exigências de implantação de gestão da qualidade no ciclo do sangue, incluindo a aplicação de Boas Práticas de Fabricação (BPF). Nos procedimentos transfusionais, encontraram-se importantes e frequentes erros, o que corrobora o descrito na literatura (VUK ET AL., 2012).

Há uma dificuldade de se implantar gestão 
de qualidade nos grandes $\mathrm{SH}$ que realizam atividades produtivas, mas aumenta ainda mais esta dificuldade quando se trata de um $\mathrm{SH}$ inserido na lógica assistencial hospitalar, como é o caso da AT. Segundo Paim et al. (2011), apesar da crescente conscientização e dos estudos em mecanismos de garantia da qualidade da atenção à saúde no Brasil, ainda é necessário avançar para assegurar padrões consistentemente elevados. Espera-se que, com o desenvolvimento de instrumentos para a segurança do paciente em ambientes de cuidado à saúde, utilizem-se mais os princípios da gestão da qualidade e do gerenciamento de risco, o que contribuirá para a segurança do ato transfusional.

A complexidade dos problemas que envolvem produtos e processos dos $\mathrm{SH}$ e suas relações de âmbito técnico, econômico, social e político dificultam o desenvolvimento de metodologias de avaliação que abarquem todos os aspectos relacionados ao risco. A compreensão desta limitação é importante na análise dos resultados deste estudo, considerando que o MARPSH propõe a sistematização de riscos potenciais relacionados aos aspectos da estrutura e do processo de serviços de hemoterapia como um mecanismo pró-ativo de prevenção a danos. Assim, a classificação atribuída ao serviço avaliado, por este método, mensura a possibilidade de ocorrência de agravos e a fragilidade dos sistemas de controle utilizados, não sendo, portanto, uma estimativa de riscos reais.

Outras limitações merecem ser apontadas para melhor entendimento dos resultados apresentados. Primeiramente, é necessário considerar que a amostra de serviços foi de conveniência, impossibilitando generalização. Além disso, os resultados apresentados são preliminares, referentes aos dois primeiros anos de acompanhamento, pela Visa, de 560 serviços hemoterápicos avaliados, não podendo ser considerados, portanto, como uma análise de tendência. Também se deve considerar a possibilidade de viés de aferição, uma vez que estas avaliações são realizadas por profissionais de variados níveis de formação técnica e experiência profissional, que não foram padronizados para a coleta dessas informações. Outra dificuldade observada foi o manejo de grandes volumes de dados em planilhas do software Microsoft Office Excel, dificultando as análises e o cruzamento de dados, comprometendo a robustez das informações.

\section{Conclusão}

A conclusão deste estudo é que, apesar dos avanços observados ao longo dos últimos 20 anos na hemoterapia brasileira, ainda persistem riscos potenciais que precisam ser analisados e tratados para a adequação dos serviços. O cenário que se espera é a redução progressiva dos índices de A, MA e M, e a concentração dos serviços de hemoterapia em MB e B. Os marcadores de risco identificados neste estudo podem conduzir à avaliação, ao monitoramento, ao planejamento, à priorização e à pactuação por parte de todos os envolvidos na busca pela segurança transfusional.

Os resultados apresentados ganham maior importância quando são utilizados nas mesas de negociação entre Visa e serviços de hemoterapia, na pactuação dos melhores caminhos para a adequação, além de subsidiarem a atualização dos instrumentos regulatórios e normativos, trazendo à luz das avaliações normativas, marcadores ou indicadores de controle de qualidade cada vez mais eficazes.

O acompanhamento da evolução temporal do risco potencial pode evidenciar avanços ou retrocessos, transformando os resultados do MARPSH em sinalizadores, o que possibilitará ações de prevenção de riscos por meio da antecipação e interrupção de uma tendência. Todos esses desafios exigirão um diálogo permanente entre os serviços de 
hemoterapia, a indústria de materiais, equipamentos e insumos de uso, os profissionais de saúde, as associações de pacientes, o SNVS e o Ministério da Saúde.

Conclui-se que o MARPSH é um instrumento útil ao trabalho de inspeção e monitoramento do perfil sanitário de serviços de hemoterapia pela Visa, com variadas possibilidades de análises, desde um recorte geral da situação de risco sanitário no País, por macrorregiões, por estado, por tipologia de serviços, natureza jurídica, até por tipo de não conformidade aos requisitos legais. $\mathrm{O}$ instrumento pode ser aprimorado em sua forma de utilização por profissionais qualificados, o que demanda constante atualização, treinamento e padronização de técnicas de coleta de dados.

\section{Referências}

AGÊNCIA NACIONAL DE VIGILÂNCIA SANITÁRIA (ANVISA). Boletim Anual de Produção Hemoterápica. 2012. Disponível em: <http://portal.anvisa.gov.br/ wps/wcm/connect/8dc8da804d5ad985ad9dedcll $6238 \mathrm{c} 3 \mathrm{~b} / 2+$ Boletim+de+producao+hemoterapica pdf?MOD=AJPERES $>$. Acesso em: 26 jan. 2016.

I Conferência Nacional de Vigilância Sanitária:

Relatório Final. Brasília, DF: Anvisa, 2001.

CONTANDRIOPOULOS, A. P. et al. Avaliação na Área da Saúde: Conceitos e Métodos. In: HARTZ, Z. M. A. (Org.). Avaliação em Saúde: dos modelos conceituais à prática na análise da implantação de programas. Rio de Janeiro: Editora Fiocruz, p. 27-48, 1997.
Outra recomendação, no aprimoramento do método, diz respeito à sua forma de análise, com utilização de sistemas informatizados, o que poderá otimizar as análises e sua utilização em rotinas de avaliação dos serviços hemoterápicos, tanto em nível local como em regional ou nacional, garantindo robustez às análises e informações, em tempo oportuno para a tomada de decisão.

E, por último, mas não menos importante, salienta-se a necessidade de parceria com centros de pesquisas científicas e universidades na investigação de novas tecnologias para o uso racional do sangue, com segurança e qualidade, e com mecanismos regulatórios eficientes, de forma que possibilite à Visa o aprimoramento de sua capacidade avaliativa

ENGLAND. Medicines and Healthcare Products Regulatory Agency. [Internet]. Report on the UK Regulation of Blood Safety and Quality 2005-2010. 2012. Disponível em: <http://www.mhra.gov.uk/ Safetyinformation/Reportingsafetyproblems/Blood/ index.ht>. Acesso em: 26 jan. 2016.

EPSTEIN, J. S.; HOLMBERG, J. A. Progress in monitoring blood safety. Transfusion, Bethesda, n. 50, p. 1408-12, 2010.

EUROPEAN UNION. Directive 2002/98/EC of the European Parliament and of Council setting standards of quality and safety for the collection, testing, processing, storage and distribution of human blood and blood components. [Internet]. Official Journal of the European Union. 2003. Disponível em: <https:// 
www.edqm.eu/sites/default/files/directive_2002_98_ ec_quality_and_safety_of_blood_components_ january_2003.pdf>. Acesso em: 29 jan. 2016.

LEITE, H. J. D. Vigilância Sanitária em Serviços de Saúde: Risco e Proteção da Saúde em Serviços de Hemodiálise. 2007, 129 f. Tese (Doutorado em Saúde Coletiva) - Universidade Federal da Bahia, Salvador, 2007.

LUCCHESE, G. Globalização e regulação sanitária: os rumos da vigilância sanitária no Brasil. 2001. 296 f. Tese (Doutorado em Saúde Pública) - Fundação Oswaldo Cruz, Rio de Janeiro, 2001.

MURPHY, M. F.; STANWORTH, S. J.; YAZER, M. Transfusion practice and safety: Current status and possibilities for improvement. Vox Sang; Oxford, v. 100, p. 46-59, 2011.

NAVARRO, M. V. T.; COSTA, E. A.; DREXLER, G. G. Controle de riscos em radiodiagnóstico: uma abordagem de vigilância sanitária. Ciênc. Saúde Colet., Rio de Janeiro, v. 15, n. 3, p. 3477-86, 2010.

OBSY, M. A. et al. Safe handling and administration of blood components: review of practical concepts. Arch. Pathol. Lab. Med., Northfield, v. 131, n. 5, p. 690-4, May 2007.

PAIM, J. et al. O sistema de saúde brasileiro: história, avanços e desafios. The Lancet, Londres, v. 377, n. 9779, p. 1778-97, 2011.

PHARMACEUTICAL INSPECTION CORPORATION SCHEME. (PIC/s) GMP Guide for Blood

Establishments. 2007. Disponível em: <http://www. picscheme.org/publication.php?download\&file=cGUt MDA1LTMtcG ljcylnbXAtZ3VpZGUtZm9yLWJsb29kL WVzdGFibGlzaG1lbnRzLnBkZg>. Acesso em: 28 jan. 2016.
RAMOA, A.; MAIA, S.; LOURENÇO, A. A Rational Framework for Production Decision Making in Blood Establishments. Journal of Integrative Bioinformatics, Bielefeld, v. 9, n. 3, p. 204, 2012.

SANTOS, L. A. C.; MORAES, C.; COELHO, V. S. P. A hemoterapia no Brasil de 64 a 80. Physis, Rio de Janeiro, v. 1, n. 1, p. 161-182, 1991.

Os anos 80: a politização do sangue. Physis, Rio de Janeiro, v. 2, n. 1, p. 107-149, 1992.

SILVA JÚNIOR, J. B.; RATTNER, D. Segurança transfusional: um método de Vigilância Sanitária para a avaliação de riscos potenciais em serviços de hemoterapia. Vigilância Sanitária em Debate, Rio de Janeiro, v. 2, n. 2, p. 43-52, 2014.

VICTORA, C. G.; BARRETO, M. L.; LEAL, M. C. et al. Health conditions and health-policy innovations in Brazil: the way forward. The Lancet, Londres, v. 377, n. 9782, p. 2042-53, 2011.

VUK, T. et al. Error management in blood establishments: results of eight years of experience (2003-2010) at the Croatian Institute of Transfusion Medicine. Blood Transfus, Milano, n. 10, p. 311-20, 2012.

ZOU, S. et al. Prevalence, incidence, and residual risk of human immunodeficiency virus and hepatitis $\mathrm{C}$ virus infections among United States blood donors since the introduction of nucleic acid testing. Transfusion, Bethesda, n. 50, p. 1495-504, 2010.

HEALTH ORGANIZATION (WHO). WHO Expert Committee on Biological Standardization. WHO guidelines on good Manufacturing Practices for Blood Establishments. Technical Report Series, Genebra, n. 961, 2011, p. 146-214.

\footnotetext{
Recebido para publicação em junho de 2015

Versão final em janeiro de 2016

Conflito de interesses: inexistente

Suporte financeiro: não houve
} 